\title{
Amerika
}

Mémoires, identités, territoires

16 | 2017 :

Les féminismes en Amérique latine et dans les Caraïbes (XXe-XXIe s) : identités et enjeux

Dossier "Les féminismes en Amérique latine et dans les Caraïbes (XXe-XXle) : identités et enjeux"

Combats féministes

\section{"Mi cuerpo es mío". Debates y disputas de los feminismos argentinos en torno al aborto y al sexo comercial}

\author{
SANTIAgo MorCILlo AND KaRINA FELITTI
}

\begin{abstract}
s
English Español

In Argentina the slogan "my body is mine" is present in the struggles for the legalization of abortion and in the claims for the recognition of sex work. In the first case there is a consensus among the different feminisms about the need and relevance of this demand, but when it comes to defending the autonomy of women in relation to commercial sex, the issue divides them. This article describes these two scenarios and puts them in relation, underlining the different interpretations that the idea of private property of the body can present in the feminisms, from the analysis of some of its theoretical productions, written documents, websites, declarations in the press and social networks.

En la Argentina la consigna "mi cuerpo es mío" está presente en las luchas por la legalización del aborto y en los reclamos por el reconocimiento del trabajo sexual. En el primer caso existe un consenso entre los diferentes feminismos sobre la necesidad y relevancia de esta demanda, pero cuando se trata de defender la autonomía de las mujeres en relación al sexo comercial el tema los divide. Este artículo describe estos dos escenarios y los pone en relación, subrayando las diferentes interpretaciones que puede presentar la idea de propiedad privada del cuerpo en los feminismos, a partir del análisis de algunas de sus producciones teóricas, documentos escritos, sitios web, declaraciones en medios de prensa y redes sociales.
\end{abstract}




\section{Index terms}

Keywords : Feminisms, abortion, prostitution, autonomy, Argentine

Palabras claves : Feminismos, aborto, prostitución, autonomía, Argentina

\section{Full text}

\section{Introducción}

"Mi cuerpo es mío" es una consigna que está presente en las movilizaciones feministas contemporáneas y un tema de estudio en la academia que se ocupa de temas de género y sexualidad (Correa y Petchesky, 1999). La vinculación de este lema con el liberalismo ha llevado a resaltar que la defensa del cuerpo como propiedad no implica dejar de lado la responsabilidad colectiva, ni la reflexión teórica y política constante (Petchesky, 1995 ; Phillips, 2013). El reclamar el derecho a la propiedad del propio cuerpo nos enfrenta a una paradoja :

aunque luchemos por los derechos sobre nuestros propios cuerpos, los cuerpos por los que luchamos nunca son lo suficientemente nuestros. El cuerpo tiene una dimensión invariablemente pública. Constituido en la esfera pública como fenómeno social, mi cuerpo es y no es mío (Butler, $2006:$ 52).

En la Argentina este lema está presente en las luchas por la legalización del aborto y también en los reclamos por el reconocimiento del trabajo sexual. En el primer caso, existe un consenso entre los diferentes feminismos sobre la necesidad y relevancia de esta demanda. Cuando se trata de defender la autonomía en relación al sexo comercial, en cambio, el tema los divide. Estas discusiones están inscriptas en un escenario en donde el feminismo ha ganado presencia pública y se realizan multitudinarias manifestaciones contra la violencia de género ${ }^{1}$. A su vez, desde comienzos del nuevo siglo algunos derechos reproductivos y sexuales fueron reconocidos legalmente -acceso a la anticoncepción (incluida la quirúrgica), educación sexual, matrimonio igualitario, identidad de género, entre otros-, pero la ambigüedad prima en torno al aborto y a la prostitución.

3 Interrumpir voluntariamente un embarazo ha sido ilegal desde fines del siglo XIX y según el artículo 86 del Código Penal, solo se considera no punible si tiene el fin de evitar un peligro para la vida o la salud de la "madre" y "si el embarazo proviene de una violación o de un atentado al pudor cometido sobre una mujer idiota o demente". Aún en estos casos aparecen diferentes obstáculos que impiden este acceso y generan las reacciones de organismos de derechos humanos y feministas. Frente a esto, en 2012, la Corte Suprema de Justicia (2012) aclaró que toda mujer que resultara embarazada como producto de una violación, debía tener acceso a un aborto no punible sin necesidad de intervención judicial y exhortó a que cada jurisdicción redactase su propio protocolo de atención para garantizarlo, lo que resultó un avance en un contexto todavía restrictivo (Ramos ; Romero y Aizemberg, 2014 ; Ramón Michel, Ramos y Romero, 2013)².

4 La prostitución no aparece directamente como ilegal en la legislación, pero desde 1921 el Código Penal sanciona la explotación de la prostitución ajena. Además, en la mayoría de las provincias hay normativas de menor alcance (códigos contravencionales) que construyen un complejo patchwork y sancionan el sexo comercial callejero - aún cuando sea autónomo-, principalmente bajo la figura de "prostitución escandalosa" (Morcillo y Justo, 2012). En la última década, la lucha contra la "trata de personas con fines de explotación sexual" habilitó enfoques que se acercan al prohibicionismo. La última modificación de la ley de trata en 2012, amplía el espectro de casos que pueden ser considerados como "trata" y desestima el consentimiento, así borra la posibilidad de que el 
sexo comercial sea una opción y devalúa las voces de las mujeres. En este marco, se han multiplicado las normas que prohíben la habilitación de cabarets y la publicación de avisos para ofertar servicios sexuales.

5 Este artículo pone en relación estos dos debates del feminismo argentino contemporáneo, el que rodea a la legalización del aborto y el que se enfoca en el sexo comercial, subrayando las diferentes interpretaciones que puede adquirir la consigna "mi cuerpo es mío". Se describen estos dos escenarios y se los pone en relación, subrayando las diferentes interpretaciones que puede presentar la idea de propiedad privada del cuerpo en los feminismos, a partir del análisis de algunas de sus producciones teóricas, documentos escritos, sitios web, declaraciones en medios de prensa y redes sociales.

\section{El derecho al aborto : quiénes, cómo, dónde}

Como dijimos, desde la salida de la crisis del 2001 en la Argentina se avanzó en el campo de los derechos sexuales y reproductivos pero no se logró legalizar el aborto, lo que constituye para los feminismos una "deuda de la democracia" (Belucci, 2014)3. El activismo religioso anti derechos sexuales y reproductivos ha tenido un rol clave en esta rémora (Pecheny, Jones y Ariza, 2016 ; Esquivel 2009 ; Vaggione 2010 ; Irrazábal 2016 ; Felitti, 2011 ; Vacarezza, 2013) y tampoco los/as representantes políticos incluyen el tema en la agenda de discusiones parlamentarias. Una estrategia de los grupos anti derechos ha sido asociar al aborto con el terrorismo de estado y así reclamar por la vida de los "bebés desaparecidos en democracia" (Gudiño Bessone 2013, Felitti 2011), vinculación que, como veremos más adelante, también se plantea en relación a la cuestión de la trata de personas.

7 Dentro de los feminismos una forma de visibilizar la necesidad de la legalización es exponer los datos estadísticos que muestran la cantidad de muertes que se producen por abortos clandestinos, destacando que es la primera causa individual de muerte materna (DEIS, 2016 :126). Lo que se destaca así es el problema de salud pública que implica la ilegalidad y la obligación del Estado de garantizar el derecho a la salud de las mujeres.

8 El otro argumento, que en general va de la mano, se concentra en el derecho de las mujeres a decidir sobre su propio cuerpo : aunque no hubiera una sola mujer muerta por aborto éste debería ser legal y gratuito. Si bien este enfoque pone el acento en la autodeterminación personal y evita colocar a las mujeres en un lugar de víctimas, la opinión pública suele ser más sensible frente a la primera descripción. Según una encuesta, existe mayor consenso en rechazar la penalización que en apoyar la legalización : la mujer no debería ir a la cárcel pero el aborto no debería ser legal. El apoyo aumenta cuando peligra la vida o la salud de la mujer o si se trata de un embarazo producto de una violación, y baja en situaciones como fallas en la anticoncepción, razones económicas o la voluntad de la mujer de no tener hijos (Andia, Brown y Pecheny, 2011). En relación a esta discrepancia, Marta Lamas, referente del proceso de legalización del aborto en la Ciudad de México en 2010, señaló :

Si yo digo 'mi cuerpo es mío y hago lo que quiero con él', de alguna manera estoy irritando a mucha gente, porque si tu cuerpo es tuyo el señor de enfrente no se siente comprometido. Si yo en cambio digo 'el aborto es un problema de salud pública, un problema de justicia social y un problema de la democracia', voy a encontrar que hay mucha gente que se siente tocada o aludida (citada en Monfort, 2010).

9 La puesta en vigencia de los protocolos de atención en casos de aborto no punible ha hecho posible también que algunos se realicen en hospitales, algunos de los cuales cuentan con consejerías de atención pre y post aborto (Dosso, 2013). Fuera de este sistema, existen organizaciones feministas o sociales que informan y acompañan a las mujeres durante la interrupción de sus embarazos utilizando misoprostol${ }^{4}$ y algunas de ellas fueron pioneras 
en esta tarea. En 2009 la agrupación Lesbianas y Feministas por la Descriminalización del Aborto lanzó la línea telefónica "Más información, menos riesgo" y produjo el manual Todo lo que querés saber sobre cómo hacerse un aborto con pastillas. Luciana Sánchez, una de sus referentes, explicaba su rechazo a la victimización : "Si las mujeres la pasan mal, es por los obstáculos que se les pone para concretarlo y, aun así, cuando lo politizás desde la mirada lesbiana del aborto, lo que sentís es orgullo" (Guzmán, 2013). Sánchez cuestionaba al feminismo heteronormativo, al que ligaba a una clase que podía pagar un aborto quirúrgico ; el "aborto popular" que la organización reclamaba, en cambio, era el que se podía hacer en la casa5. En su crítica aparecía la cuestión sobre los sujetos del aborto :
Desde el paradigma heterosexual del aborto no se plantea que las lesbianas aborten, que los varones trans aborten, que las travestis tengan una participación activa en actuar, hacer y pensar los abortos. Es pensar el sexo desde lo heterosexual, desde la cohabitación, la repetición, la penetración. Lo vemos en esta idea de que si a la gente la llenamos de anticonceptivos, se acaba el aborto. Eso es falso y atenta contra la autonomía de las personas. (Lesbianas y feministas por la descriminalización del aborto, 2014).

En esta línea, en la contratapa de una edición del manual, aparece la muñeca Barbie relatando que le fue "Bárbaro" con las pastillas de misoprostol. El empoderamiento, la agencia y la libertad que puede expresar el aborto, se personifica en un icono de la cultura de masas -denunciado por el feminismo por promover ideales corporales imposibles- que al relatar su propio aborto asume un lugar ya no anclado en su belleza estereotípica sino en su capacidad de decisión ${ }^{6}$.

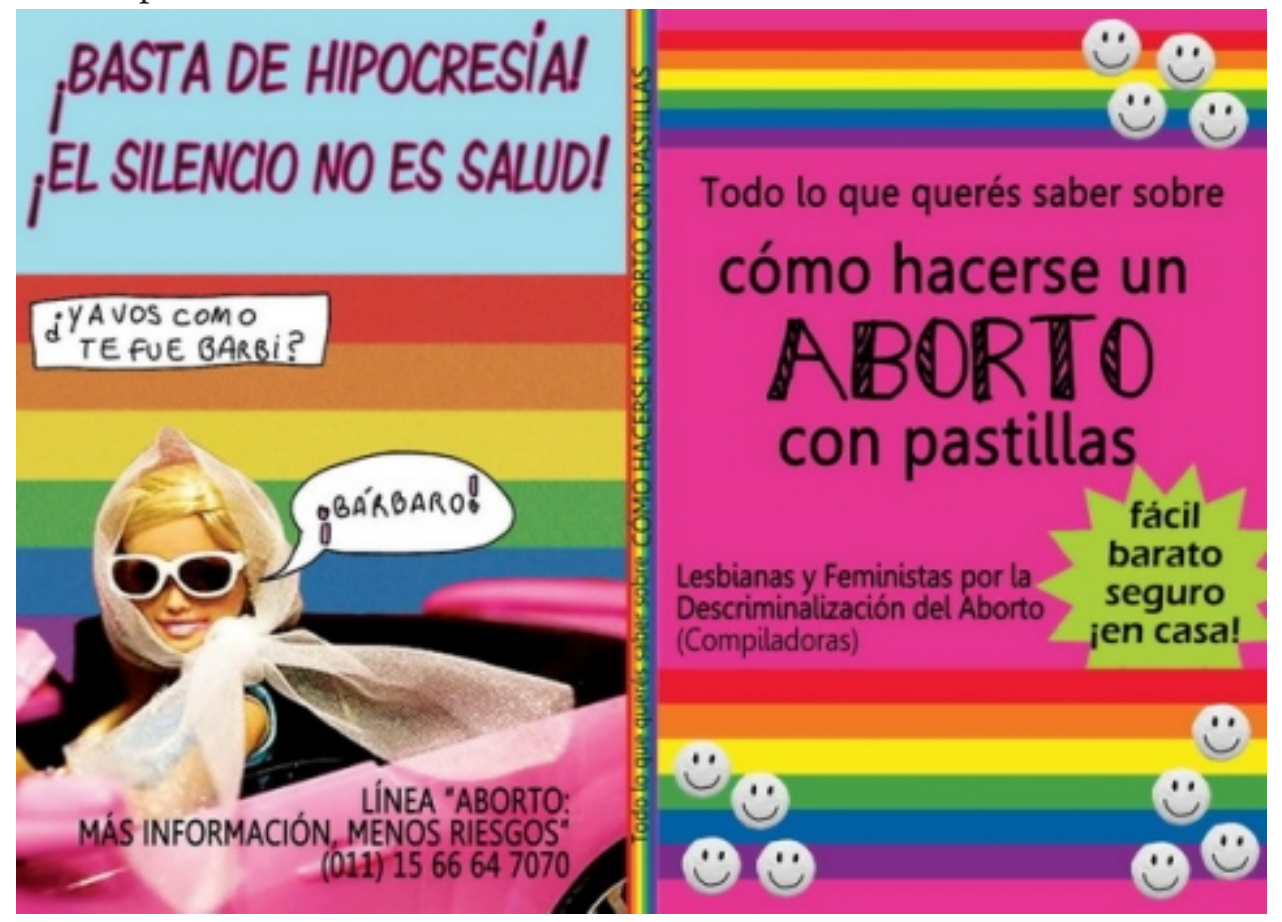

Portada y contratapa del libro de Lesbianas y Feministas por la Descriminalización del Aborto (compiladoras) Todo lo que querés saber sobre cómo hacerse un aborto con pastillas, Editorial El Colectivo, Buenos Aires, 2010.

Las Socorristas en red. Feministas que abortamos son una red de activistas articuladas en torno a su trabajo como "socorristas". Los "socorros rosas" toman el nombre en clave genealógica y recuperan la experiencia de acompañamientos que hacían las feministas italianas, francesas y estadounidenses en las décadas del ' 60 y del '70.7 Su sitio web muestra una estética juvenil y descontracturada : pares de zapatillas de un modelo de moda y color fucsia, dan una idea de movimiento, de rapidez, de disposición para salir al socorro de las mujeres que las necesiten. ${ }^{8} \mathrm{Al}$ igual que la contratapa con la imagen de Barbie, la propuesta es sacar al aborto de las sombras y de lo sombrío para considerarlo un 
episodio de la vida sexual y (no) reproductiva de las mujeres. Con ese objetivo, en 2015 produjeron un libro que recoge las experiencias de varias mujeres a quienes acompañaron. En el prólogo Nayla Vacarezza destaca :

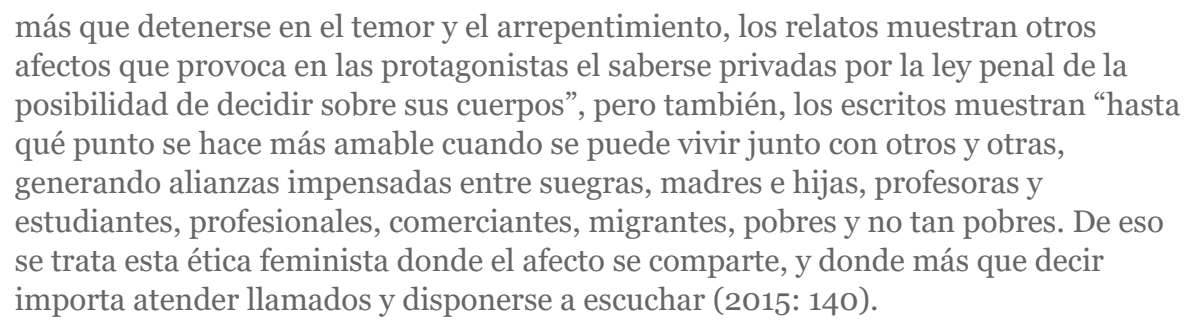

En este conjunto de relatos la reapropiación del cuerpo pasa por un proceso de alianzas y en ese sentido rompe el caparazón individual: sostener que "mi cuerpo es mío" se hace posible por una ligazón entre mujeres, por una red.

Otro ejemplo de estas solidaridades es la Campaña Nacional por el Derecho al Aborto legal, Seguro y Gratuito, organizada a partir del el XVIII Encuentro Nacional de Mujeres de Rosario (2003) ${ }^{9}$, impulsada por grupos feministas, del movimiento de mujeres y mujeres de movimientos políticos y sociales. La Campaña articula argumentos al postularlo como una cuestión de salud pública, de justicia social y de derechos humanos de las mujeres. El espacio central que éstas ocupan en la Campaña también ha suscitado debates sobre el lugar de los varones y personas trans en esta lucha (Chaher, 2014), pero aún así, el reclamo por la legalización del aborto no se pone en cuestión, incluso entre las activistas feministas de izquierda -por ejemplo, Las Rojas del partido Nuevo MAS-, que en cambio si son reactivas a las posiciones que ellas llaman "pro-sexo".

\section{¿Durmiendo con el enemigo? La polarización de los feminismos argentinos en torno a la prostitución}

Desde la década de 1980, la prostitución comenzó a ser objeto de un debate, primero en el ámbito euro-norteamericano y luego global. Las posiciones han tendido a polarizarse : una legitima la prostitución y la concibe como "trabajo sexual" y otra la entiende como una forma de violencia de género y pretende abolirla. En torno a la primera postura, se articulan los movimientos de prostitutas que surgieron en los años 70' para luchar contra el hostigamiento policial y la estigmatización de las putas. Justamente la activista y prostituta Carol Leigh, explica que acuñó la expresión "sex worker" por los problemas que causaba presentarse como "prostituta" en contextos feministas. Otras, como la brasilera Gabriela Leite, sostuvieron la idea de reivindicarse directamente como "putas" y cambiar el sentido degradante de este significante (Pheterson, 1989).

En los 80' los movimientos de prostitutas emergen en América Latina y en la década siguiente se mundializan bajo la influencia de la epidemia de VIH/sida (Lamas, 1993), el feminismo -aunque dividido-, el aumento de las migraciones a nivel global y la apertura de los sindicatos a nuevas formas de organización y profesiones (Gall, 2007).

16 En esa época, en la Argentina, el debate no estaba tan polarizado. Por ejemplo, Marta Fontenla, reconocida abolicionista, apoyaba los intentos de organización de algunas prostitutas : "La prostitución ES ahora una institución social, basada en la explotación de las mujeres, aunque clandestina y reprimida ¿Y qué otra forma tiene un explotado/a de luchar por su liberación que organizarse para esta lucha ?” (1985 : 29-30 énfasis en el original).

17 Incluso a mediados de los 90', las concepciones sobre el uso del cuerpo y la sexualidad podían ponerse entre paréntesis a la hora de construir articulaciones contra el 
hostigamiento policial, como se demostró en la lucha contra los edictos policiales de Buenos Aires en la que se articularon, entre otras, la organización abolicionista "Asamblea Raquel Liberman" y las trabajadoras sexuales de AMMAR (Asociación de Mujeres Meretrices de Argentina) que nucleaba desde 1995 a las prostitutas (Morcillo y Varela, 2017) ${ }^{10}$.

Una particularidad del movimiento de prostitutas argentino fue su temprano acercamiento a las fuerzas sindicales, especialmente a la CTA (Central de Trabajadores de la Argentina) y una relación más tardía con algunas vertientes del feminismo. La alianza con este "nuevo sindicalismo" posibilitó sumar a los usos tácticos de la idea del "trabajo" un repertorio de reivindicaciones ligadas a los/as trabajadores/as y el mundo del trabajo. Así, la idea de "trabajo sexual" se cargó de un discurso obrerista y de una lógica más colectiva que la que parecía primar entre sus pares del norte (Morcillo, 2014). Por contrapartida, así como las prostitutas activistas en San Francisco enarbolaban la idea del sex work con una fuerte dosis de crítica a la moral sexual burguesa -y no tanto hacia la ética laboralista del capitalismo-, en Argentina las trabajadoras sexuales hacían clara su pertenencia a la clase obrera, aunque sin lanzar (aún) un cuestionamiento más explícito hacia las posibilidades de reapropiación de la sexualidad femenina. Elena Reynaga, una de las fundadoras de AMMAR, se definía así : "No soy puta, no soy prostituta, no soy trapo ni jinetera. No soy cuero, no soy meretriz ni ramera, tampoco cortesana. Soy una mujer trabajadora, una mujer trabajadora sexual"11.

19 Es en paralelo al endurecimiento de las posiciones abolicionistas en el feminismo vernáculo que las prostitutas profundizan sus críticas de género y se preguntan por su lugar en las filas del feminismo. A su vez, uno de los vectores que acelera la polarización de los debates es la reaparición de la cuestión de la "trata de personas con fines de explotación sexual" que toma fuerza a partir del 2000. Aquí resuenan elementos de la lucha del abolicionismo contra la "trata de blancas" de 150 años atrás : las alianzas con los sectores religiosos conservadores y la adopción de una retórica que plantea la lucha como una cruzada, un clima de pánico moral y la sobredimensión del fenómeno. Esta reaparición produce un aplanamiento de las distintas inserciones en el mercado sexual y su homogeneización bajo la idea de trata (Doezema, 2000 ; Weitzer, 2007). La construcción de este tema como una cuestión supranacional y los mecanismos implementados desde la administración Bush en EE.UU., junto a la fuerte mediatización de casos devenidos emblema y a la producción de cifras de "víctimas rescatadas", fueron algunos de los elementos que coadyuvaron al resurgimiento del discurso anti-trata en Argentina (Justo von Lurzer, 2011 ; Morcillo y Varela, 2017 ; Varela, 2015a ; Varela y Gonzalez, 2015).

Como vimos en relación al aborto, el discurso de los derechos humanos es utilizado por ambas posiciones : "las trabajadoras sexuales tenemos derechos básicos que nos asisten como seres humanos, como mujeres y como trabajadoras" se lee en el sitio web de AMMAR ; mientras que el feminismo abolicionista traza paralelos entre las víctimas de trata y las desparecidas de la dictadura (Varela, 2015b). En esta línea, Sonia Sanchez, exprostituta y reconocida militante abolicionista sostiene

\footnotetext{
La prostitución tiene todos los síntomas de un campo de concentración. Y de hecho, hoy las mujeres que desaparecen en la prostitución, y no hablo de desaparecidas simbólicas sino concretas, desaparecen con la trata de personas [...] Cuando hablo de campo de concentración es porque veo que los penes son picanas. Y cuando una mujer se mete en un hotel transitorio para ser penetrada bucal, anal y vaginalmente, se está jugando la vida. La marca que se deja a la puta, como a los judíos con el número, es la vergüenza. Por eso las putas tienen otros nombres. No tienen verdadera identidad. Y al dolor lo maquillan con ese orgullo que implica el discurso de "con ese dinero yo les doy de comer a mis hijos" o "yo pongo el precio", etc... (entrevista Radio Kermes, 2015).
}

Este discurso sin matices posiciona a las prostitutas organizadas como trabajadoras sexuales como el principal enemigo, aliadas de los proxenetas o directamente "fiolas 
sindicalistas" (Galindo y Sanchez, 2007).

Estas concepciones habilitan el efecto metonímico que aparece cuando se plantea que en la prostitución "se vende el cuerpo". En una retórica donde resuena el feminismo radical norteamericano, Sánchez sostiene que "cuando convierten a una mujer en puta, no la reducen a un cuerpo, sino a boca, vagina y ano"12. La negación total de cualquier capacidad de agencia para las mujeres que venden sexo va incluso más allá de la apropiación del cuerpo por el patriarcado, ahora este cuerpo aparece reducido a orificios, la autonomía en relación al cuerpo desaparece completamente. La puta es vista como un sujeto arrasado, para Sánchez, "no hay prostitución autónoma, puedes disfrazarla como quieras, pero autonomía en la prostitución no hay, una puta es una persona cosificada (...) es una persona destruida totalmente" (entrevista en La cultura nuestra, 2015).

Por su parte, las trabajadoras sexuales organizadas han trazado distinciones entre la trata de personas y el trabajo sexual, sin negar las situaciones extremas pero señalando diversos márgenes de autonomía. No obstante, la perspectiva jurídica del consentimiento remite a una concepción liberal donde la elección aparece como un acto individual y así constituye un terreno complejo para construir una argumentación que dé cuenta de las vulnerabilidades y opresiones sin anular completamente los grados de autonomía.

La respuesta de AMMAR articula su inserción de clase y el cuestionamiento a los significados asociados a la sexualidad :

nos resulta hasta gracioso que nos digan que nosotras vendemos nuestro cuerpo y hasta el momento todas tenemos nuestro cuerpo entero, en todo caso sufrimos la explotación que cualquier mujer sufre en un sistema injusto y patriarcal, o las obreras textiles que trabajan en las maquilas nos son explotadas ?, ¿y por eso debemos considerarlas indignas? (AMMAR, 2006).

A su vez, Georgina Orellano, la actual secretaria general de AMMAR, ha buscado matizar ciertas interpretaciones de la trabajadora sexual como absolutamente libre :

ningún trabajador va a trabajar feliz todos los días, en ningún mercado laboral. Un trabajador no elige, termina siendo explotado porque el sistema capitalista termina explotando. Por eso también existen los sindicatos, se agrupan y organizan. Pero en vez de prohibir nuestra actividad, en vez de controlar cuerpos ajenos, a la vez el Estado tiene que dar un marco regulatorio, otorgar derechos laborales, mejorar las condiciones para quienes sí queremos seguir en la actividad pero en mejores condiciones. El Estado podría atender a los dos sectores : la reinserción de quien no quiere ejercer más esta actividad, pero atender a quienes sí (Entrevista en Radio Kermes, 2016).

Aquí también busca desarmar el antagonismo con las que se autodenominan "mujeres en situación de prostitución” nucleadas en AMADH (Asociación de Mujeres Argentinas por los Derechos Humanos) ${ }^{13}$ que demandan asistencia al Estado y una reinserción laboral, planteando que esta política puede convivir con la despenalización y la regulación con derechos laborales para las que quieren continuar en el mercado sexual.

AMMAR en la manifestación “Tetazo" 8-2-2017 en Buenos Aires14 


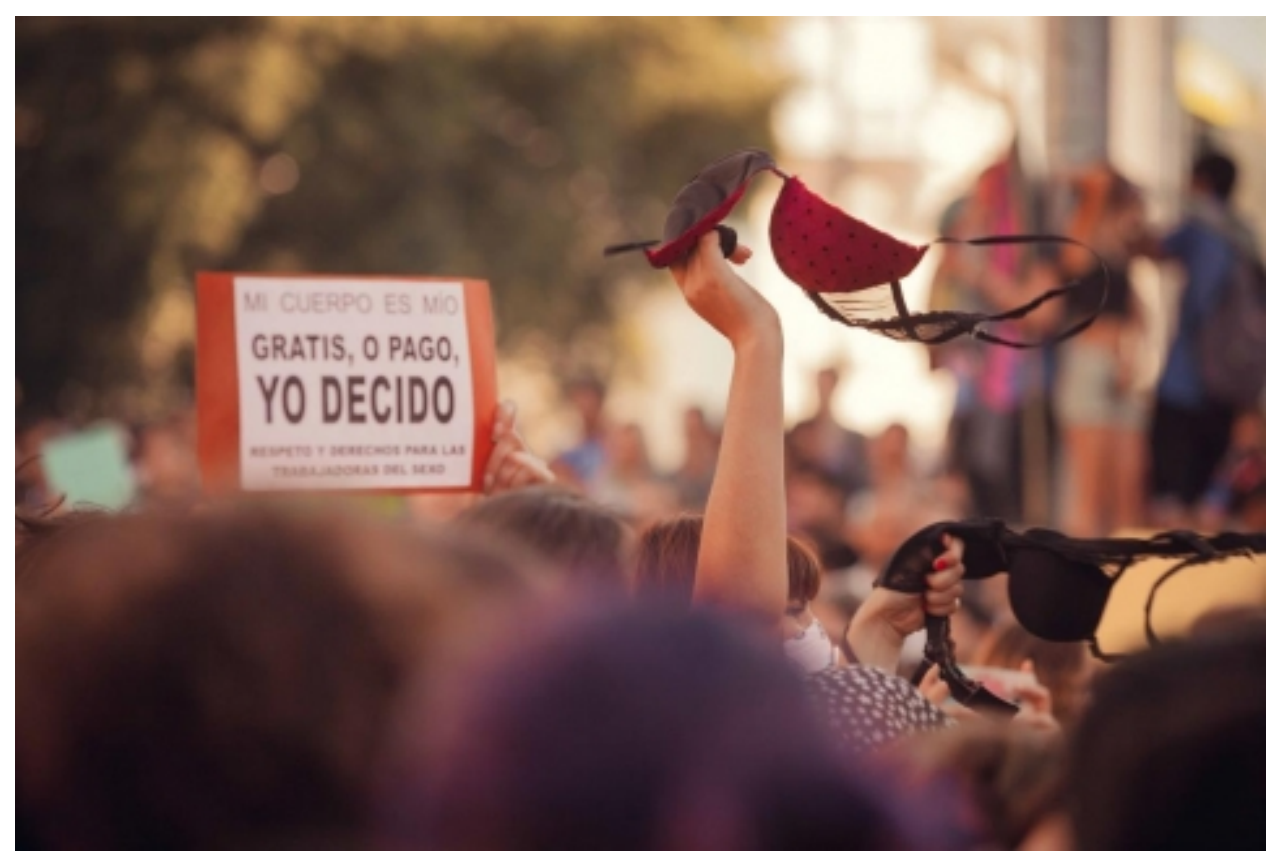

Stencil callejero en Buenos Aires "mi cuerpo no tiene precio"15 


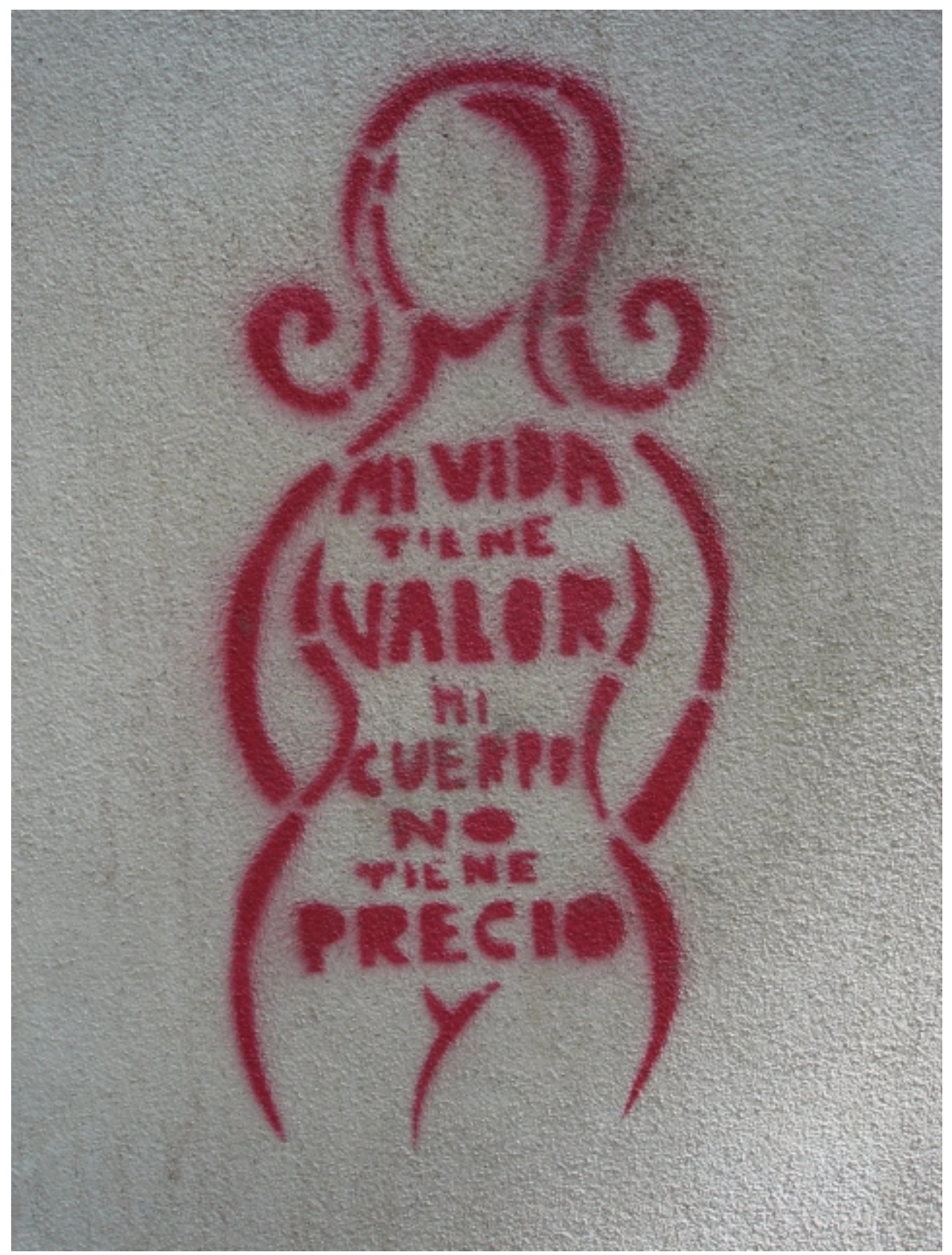

Recientemente el discurso de las trabajadoras sexuales ha calado en las camadas de jóvenes feministas con la identificación de "Puta feminista". En el discurso de Orellano se nota tanto la vuelta a la reapropiación del significante puta como la tensión que este puede tener con una sexualización no politizada :

Somos putas. Putas por elección. Nos gusta, no para acostarnos con 30 tipos por día, pero sí elegimos ejercer el trabajo sexual porque reditúa mejor económicamente que otros trabajos. Los otros trabajos a que acceden mujeres de sectores populares, son todos mal pagos. Elegimos el trabajo sexual y lo queremos seguir ejerciendo con mejores condiciones laborales. (Entrevista en Radio Kermes, 2016).

Desde el abolicionismo, en cambio, la venta de sexo jamás puede ser una forma de la libertad sexual :

Nosotras somos partidarias de la verdadera libertad sexual. Nosotros fuimos hijas de los 60. ¿Qué quiere decir eso ? Ir contra todos los estereotipos, en contra del sometimiento del ama de casa, la domesticación de la sexualidad heteronormativa y patriarcal de adentro de los hogares. Estamos en contra de eso y del uso del cuerpo de las mujeres para la prostitución ("Las razones del abolicionismo" en Página 12, 2015). 
También las mujeres de AMADH han planteado cuestionamientos en relación a la posibilidad de considerar que las mujeres puedan usar su cuerpo sexualmente para obtener rédito económico "En cualquier trabajo, vos usás tus manos. Cuando limpiás un inodoro, vos manejás tus manos. Pero si te están pagando para usar tu cuerpo, no es tu cuerpo. Es de él, porque está pagando. No es trabajo bajo ningún punto de vista”. (Entrevista en Razón y revolución, 2015).

Se disputa por los sentidos de la sexualidad y qué formas de reapropiación del cuerpo aparecen como válidas dentro de los marcos de interpretación feministas. Las trabajadoras sexuales han explicitado su apoyo a la lucha por la legalización del aborto, desde allí ponen en cuestión los límites del "mi cuerpo es mío" :

$$
\begin{aligned}
& \text { ¿Por qué decirme a mí lo que yo tengo que hacer o decirnos que no nos consideran } \\
& \text { trabajadoras, porque el cuerpo no es mercancía ? El cuerpo es mío, lo único mío que } \\
& \text { tengo. Nosotras trabajamos en contra de la violencia hacia las mujeres y después } \\
& \text { resulta que nos dicen "yo no te considero a vos trabajadora”. Eso es violento, eso no } \\
& \text { es democrático, es patriarcal. (Entrevista a Elena Reynaga, Razón y revolución, 2015) }
\end{aligned}
$$

La lectura de los posicionamientos de ciertos sectores del feminismo que apoyan la reapropiación del cuerpo en el caso del aborto, pero no cuando este es usado laboral y sexualmente es leído como un doble estándar. Así Orellano plantea "No es de Feminista andar diciéndole a otra mujer lo que debería hacer con su propio cuerpo. Si mi cuerpo es mío y yo decido, porqué no puedo cobrar por mi sexo, porque no puedo ser Puta ? No me voy a cansar de decirlo. Basta de dobles discurso" 16 .

\section{Reflexiones finales}

La descripción de dos espacios de debate feminista, sobre el aborto y la prostitución, permite reflexionar sobre distintas apropiaciones de la consigna "mi cuerpo es mío" y sobre las dinámicas de articulación o antagonismo de las organizaciones. A partir de este recorrido, nos preguntamos qué tan efectiva ha sido hasta hoy la consigna en cada caso y si es posible superar la lectura liberal individualista que rodea la idea de propiedad privada del cuerpo. Hemos visto que las organizaciones y referentes aquí citadas han planteado reapropiaciones de la consigna desde una lectura colectiva. En la lucha por la legalización del aborto, las organizaciones que sostienen la idea del derecho a abortar cimentada en el "mi cuerpo es mío" han tratado de pensar la experiencia del aborto como un evento que traza solidaridades entre mujeres y trasciende la lógica individual. "Yo aborté" es una forma de afirmarse, de visibilizar, pero la sororidad de los "socorros rosas", del acceso gratuito a información en la web, de la atención de un número telefónico, de organizaciones conectadas en red, de relatos de experiencias escritos en primera persona pero compartidos, remiten a lo colectivo, un "aborto en manada". La inclusión plantea también sus dilemas en tanto que "feministas que abortamos" deja fuera a feministas que por diferentes razones no abortan, así como la idea del aborto como derecho de las mujeres plantea qué sucede por fuera de las identidades cis sexuales y de las prácticas con consecuencias reproductivas. Aun así, la defensa de la autonomía del cuerpo de las mujeres frente a la injerencia religiosa -"saquen sus rosarios de nuestros ovarios" -, y la necesidad de la legalización aunque después se discuta si es el hospital o la casa el mejor lugar para abortar, reúne y une a diferentes feminismos y movimientos socio-sexuales.

Por su parte, las trabajadoras sexuales reclaman que si "mi cuerpo es mío" esto debería incluir el derecho a vender servicios sexuales, especialmente para aquellas mujeres que, como proletarias, sólo tienen su cuerpo como propiedad, pero por ello mismo se organizan como colectivo atravesado no sólo por las opresiones de género sino también de clase. También aquí se da una apropiación colectiva de la consigna y en este caso, no solo contestan a la ingerencia religiosa sobre sus cuerpos sino también a la de ciertos 
feminismos que, propugnando la "verdadera libertad sexual", parecen dictar qué hacer y qué no con los cuerpos de las mujeres.

¿Por qué estos escenarios son tan diferentes ? Una explicación cabal de estos procesos excede los límites de este artículo de objetivos más modestos. Sin embargo queremos dejar señalados algunos interrogantes. En primer lugar debemos pensar cómo se liga la mayor sexualización presente en el comercio sexual por comparación al aborto. Si bien la lectura lésbica y trans del aborto que proponen algunos grupos lo insertaría en una trama de sexualidades, en el caso del comercio sexual su sexualización es ineludible, tanto que las trabajadoras sexuales deben constantemente señalar su lectura laboral. Evidentemente, a diferencia de los temas más ligados a la salud reproductiva o al mercado laboral, las sexualidades siguen generando controversias mucho más fuertes en el feminismo. Si el autonomismo del "mi cuerpo es mío" genera tensiones en la lucha por el aborto, cuando ese cuerpo se sexualiza, genera rupturas. A la par de la expansión de los debates feministas -especialmente ligados a la violencia de género- en el seno de una sociedad cuya cultura aparece cada vez más sexualizada crece el interrogante sobre cómo construir concepciones de sexualidad que contengan un elemento crítico pero sin perder la polifonía.

\section{Bibliography}

Alma, Amanda y Paula Lorenzo, Mujeres que se Encuentran Una recuperación histórica de los Encuentros Nacionales de Mujeres en Argentina (1986 - 2005), Buenos Aires, Feminaria, 2009

Andia, Ana Maria ; Brown, Josefina y Pecheny, Mario, “¿A la cárcel o al sistema de salud ? Las opiniones sobre despenalización y legalización del aborto en la Argentina”, en Rosa Geldstein y Marta Schufer (comp.) Problemas actuales de salud reproductiva, familia, género y sexualidad : la investigación social de la diversidad, Buenos Aires : Biblos/PNUD, 2011

Bellucci, Mabel, Historia de una desobediencia. Aborto y feminismo, Buenos Aires : Capital Intelectual, 2014

Butler, Judith, Vida precaria. El poder del duelo y la violencia, Buenos Aires : Paidos, 2006

Doezema, Jo, "Loose Women or Lost Women? The Re-emergence of the Myth of White Slavery in Contemporary Discourses of Trafficking in Women”. Gender Issues 18, no. 1, 2000, pp 23-50.

Dosso, Daniela, "Consejería pre y post aborto. Efectos de la intervención en la salud integral de las mujeres atendidas en un Centro de Atención Primaria de la Salud de la provincia de Buenos Aires", Perspectivas bioéticas, n. 34 (18), $2013:$ 75-93.

Dworkin, Andrea, "Prostitution and male supremacy”. Michigan Journal of Gender \& Law 1, no. 1, 1993, pp 1-12.

Esquivel, Juan Cruz, "Religious and Politics in Argentina. Religious influence on parliamentary decisions on sexual and reproductive rights", Latin American Perspectives, vol. 43, 2016: 133-143

Felitti, Karina, "Estrategias de comunicación del activismo católico conservador frente al aborto y el matrimonio igualitario en la Argentina" Revista Sociedad y Religión, 34/35 : 2011, pp 92-122

Felitti, Karina, "L'avortement en Argentine. Politique, religion et droits humains", Autrepart. Revue du Sciences Sociales du Sud, 70, $2015:$ 73-90.

Fontenla, Marta. "Reflexiones sobre la prostitución". Brujas Boletín Feminista 3, no. X 1985, pp1730

Galindo, María, y Sanchez, Sonia, Ninguna mujer nace para puta. Buenos Aires: Lavaca Editora, 2007

Gall, Gregor, "Sex worker unionisation: an exploratory study of emerging collective organisation". Industrial Relations Journal 38, no. 1, 2007, pp 70-88.

Gudiño Bessone, Pablo, "Católicos y feministas : conflictos en torno al aborto y resignificaciones del pasado reciente”. Aletheia. Revista de la Maestría en Historia y Memoria de la FaHCE. Aletheia 3, 6. 2013

Irrazábal, Gabriela, “¿Bioética y Religión ? : Apuntes para comprender la imbricación de la bioética y lo religioso en la toma de decisiones en la Argentina contemporánea" Revista americana de medicina respiratoria, 16, 3, 2016, pp 290-297.

Justo von Lurzer, Carolina, Sexualidades en Foco. Representaciones televisivas de la prostitución en Argentina. Tesis de Doctorado, Facultad de Ciencias Sociales Universidad de Buenos Aires : Buenos Aires. 2011 
Lamas, Marta, "El fulgor de la noche : algunos aspectos de la prostitución callejera en la cuidad de México". Debate feminista 4, no. 8, 1993, pp 56-87

Llopis, María, Maternidades subversivas, Euskal Herria : Txalaparta, 2015

Masson, Laura, Feministas en Todas Partes. Una etnografía de espacios y narrativas feministas en Argentina, Buenos Aires, Prometeo, 2007

Morcillo, Santiago. "'Como un trabajo'. Tensiones entre sentidos de lo laboral y la sexualidad en mujeres que hacen sexo comercial en Argentina", Sexualidad, Salud y Sociedad (Rio de Janeiro) 18, 2014, pp 12-40

Morcillo, Santiago y Justo, Carolina. "Mujeres públicas' y sexo clandestino : ambigu" edades en la normativa legal sobre prostitución en la Argentina”. En Jones, D. Figari, C. y Barrón López, S. (eds) La producción de la sexualidad : políticas y regulaciones sexuales en Argentina, Buenos Aires : Editorial Biblos, 2012

Morcillo, Santiago y Varela, Cecilia, "Trabajo sexual y feminismo, una filiación borrada : traducción de "Inventing Sex Work" de Carol Leigh (Alias Scarlot Harlot)". Revista La Ventana, 5(44), 2016, pp $7-23$

Morcillo, Santiago y Varela, Cecilia, "Ninguna Mujer... El abolicionismo de la prostitución en la Argentina”, Sexualidad, Salud y Sociedad, 26, 2017 (en prensa)

Pecheny, Mario; Jones, Daniel \& Ariza, Lucía, "Sexual Politics and Religious Actors in Argentina", Religion and Gender, vol. 6, $\mathrm{N}^{\mathrm{O}}$ 2, 2016, pp. 205-225

Petchesky, Rosalind, "The Body as Property: A Feminist Re-vision". En Ginsburg F.D. \& Rapp R. (eds). Conceiving the New World Order: The Global Politics of Reproduction. Los Angeles, CA : University of California Press, 1995

Pheterson, Gail. Nosotras, las putas. Madrid: Talasa, 1989

Phillips, Anne, Our bodies, whose property?, Princeton University Press, 2013

Ramón Michel, Agustina ; Ramos, Silvina y Romero, Mariana, "Barreras en el acceso a los abortos legales : una mirada a las regulaciones sanitarias que incluyen el uso del misoprostol", en Misoprostol. Regulaciones y barreras en el acceso al aborto legal, Lima, 2013, pp 19 - 64

Ramos, Silvina; Romero, Mariana y Aizemberg, Lila, "Women's experiences with the use of medical abortion in a legally restricted context: the case of Argentina", Reproductive Health Matters, Londres, vol. , Supp, 2014, pp 4-15

Vacarezza, Nayla, "Política de los afectos, tecnologías de visualización y usos del terror en los discursos de los grupos contrarios a la legalización del aborto", en Zurbriggen R. y Claudia Anzorena (comps.) El aborto como derecho de las mujeres. Otra historia es posible, Buenos Aires, Herramienta, 2013, pp 209-223

Vacarezza, Nayla, "Aborto, experiencia, afectos", en Belfiore Daihana, Código Rosa, Relatos sobre aborto, Buenos Aires : Ediciones La Parte Maldita, 2015, pp 137-141.

Vaggione, Juan Marco (comp.), El activismo religioso conservador en Latinoamérica. Córdoba : Ferreyra Editor. 2010

Varela, Cecilia, "La campaña anti-trata en la Argentina y la agenda supranaciona"l. En Género y violencia en el mercado del sexo. Política, policía y prostitución, Daich, D. y Sirimarco, M. Buenos Aires : Biblos, 2015a

Varela, Cecilia, "La campaña anti-trata y el paradigma de derechos humanos en la Argentina." en Congreso de la Asociación de Estudios Latinoamericanos. San Juan, Puerto Rico, 2015b

Varela, Cecilia, y Gonzalez, Felipe, “Tráfico de cifras : 'desaparecidas' y 'rescatadas' en la construcción de la trata como problema público en la Argentina”. Revista Apuntes de Investigación del CECYP 26, 2015, pp 74-99

Vasallo, Marta “Prostitución : ¿violencia o libertad ?” Feminaria 12, no. 22/23, 1999: 40-47.

Weitzer, Ronald. "The Social Construction of Sex Trafficking: Ideology and Institutionalization of a Moral Crusade". Politics \& Society 35, no. 3, 2007 : 447-475.

Zurbriggen, Ruth ; María Trpin y Belén Grosso, "Decidir abortar y decidir acompañar. Socorro Rosa : Un servicio de prácticas y experiencias en clave feminista" en Zurbriggen R. y Claudia Anzorena (comps.) El aborto como derecho de las mujeres. Otra historia es posible, Buenos Aires : Herramienta, 2013, pp. 303-320.

\section{Documentos públicos y de organizaciones}

AMMAR, Boletín $N^{o}$ 1, Buenos Aires, 8 de mayo 2006

Corte Suprema de Justicia de la Nación Argentina, F. 259. XLVI.F., A. L. s/ medida autosatisfactiva, 13 de marzo 2012

\section{Artículos periodísticos}


Chaher, Sandra, “¿Puede la mujer heterosexual no ser el único sujeto de la lucha por el aborto ?”, Comunicar Igualidad, 2014, http://www.comunicarigualdad.com.ar/puede-la-mujer-heterosexualno-ser-el-unico-sujeto-de-la-lucha-por-el-aborto/

Entrevista a Elena Reynaga "Somos parte de la clase explotada", en Razón y Revolución, 4 de septiembre de 2015 http://razonyrevolucion.org/somos-parte-de-la-claseexplotada-entrevista-a-elena-reynaga-ammar-cta/

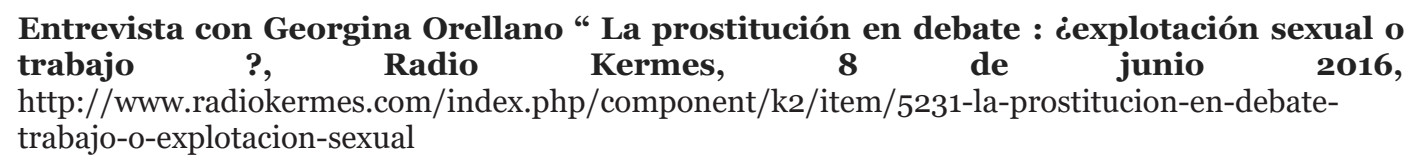

Entrevista a M. Peralta y A. Ascona (AMADH) "Exigimos al Estado una salida laboral” en Razón y Revolución, 4 de septiembre de 2015 http://razonyrevolucion.org/exigimos-al-estado-una-salidalaboral-entrevista-a-m-peralta-y-a-ascona-ammar-capital/

Entrevista con Sonia Sánchez “¿Qué derecho tiene una puta ?”, Revista La cultura nuestra, 12 junio 2015, http://laculturanuestra.com/entrevista-con-sonia-sanchez-que-derecho-tiene-una-puta/

Entrevista con Sonia Sánchez "La trata de personas y el proxenetismo son socios del discurso de trabajo sexual” en Radio Kermes, 1 de junio 2016, http://www.radiokermes.com/index.php/component/k2/item/2897-la-trata-de-personas-y-elproxenetismo-necesitan-y-son-socios-del-discurso-de-trabajo-sexual

Guzmán, Andrea, “Lesbianas por la vida”, Soy, Página 12, 23 de agosto 2013

https://www.pagina12.com.ar/diario/suplementos/soy/1-3070-2013-08-28.html

Lesbianas y feministas por la descriminalización del aborto, "El aborto lesbianiza", Soy, Página 12, 19 de abril 2014

Monfort, Flor “La mala fama. Entrevista a Marta Lamas”. Las 12. Página 12, 17 de diciembre. 2010

Santoro, Sonia "Las razones del abolicionismo", Página 12, 7 de septiembre de 2015 , https://www.pagina12.com.ar/diario/dialogos/21-281077-2015-09-07.html

Sitios web

AMMAR http://www.ammar.org.ar/-Quienes-somos-.html

\section{Notes}

1 Con epicentro en Buenos Aires y en las principales capitales provinciales, en junio de 2015, junio de 2016 y en octubre de 2016 se realizaron movilizaciones bajo la consigna Ni Una Menos, que incluyeron dos huelgas de mujeres (en octubre de 2016 y el 8 de marzo de 2017), acciones que tuvieron gran difusión internacional.

2 En 2004 el Ministerio de Salud nacional había publicado en 2004 una "Guía para el mejoramiento de la atención post-aborto" y en 2007 un protocolo de atención de embarazos no punibles, que se actualizó en 2015.

3 Para un análisis histórico del tema ver Felitti 2015.

4 El misoprostol es una droga utilizada para la prevención y tratamiento de las úlceras gástricas y duodenales, y también para la inducción del parto vaginal y abortos medicamentosos. La OMS incluyó al aborto con medicamentos en la guía técnica y de políticas para sistemas de salud "Aborto sin riesgos", en el año 2003.

5 Si bien aquí no nos ocupamos de analizar los casos de abortos espontáneos, también existe una literatura feminista que recomienda tener un aborto en casa y no en un "frio hospital" (Llopis, 2015).

6 La portada del libro, de color rosa, con el arcoíris que representa al activismo LGBT y las caritas sonrientes de "Smile" son otras formas gráficas de aportar a la "desdramatización" de la práctica. Cabe aclarar que Barbie ha sido aggiornada en el postfeminismo por su mismo fabricante -por ejemplo, con el modelo Barbie presidenta- y sigue siendo objeto de investigación de la academia, y a la vez utilizada por artistas y activistas con diferentes reapropiaciones, como el corto animado porno de la argentina Albertina Carri, Barbie también puede estar triste (2002).

7 La experiencia de socorrismo fue iniciada por la Colectiva La Revuelta, una organización feminista de la provincia de Neuquén, en 2010, primero de "boca a boca", para garantizar seguridad y evitar posibles persecuciones y luego de manera pública (Zurbriggen, Trpin y Grosso, 2013).

8 http://socorristasenred.org/

9 Sobre estos Encuentros puede consultarse Masso, 2007 y Alma y Lorenzo, 2009. 
10 Incluso a fines de los 90 podemos leer una mirada más matizada en el abolicionismo, que todavía sospechaba de las derivas prohibicionistas y las alianzas con la derecha religiosa del feminismo radical en EE.UU (Vasallo, 1999).

11 En 2003 en el Foro de VIH/Sida en La Habana

12 Esto recuerda a la definición de Dworkin : "La prostitución no es una idea. Es la boca, la vagina, el recto, penetrados usualmente por un pene, a veces por manos, a veces por objetos, por un hombre y luego por otro, y luego por otro, y luego por otro, y luego otro" (1993: 1).

13 En 2002 un grupo de mujeres comenzó a funcionar autónomamente como AMMAR Capital y acabaron escindiéndose. Al año siguiente abandonaron la CTA, fueron a un espacio cedido por la Iglesia Evangélica Metodista de Flores y pasaron a autodenominarse "mujeres en situación de prostitución”. Ellas entablaron desde su escisión vínculos con organizaciones del feminismo abolicionista.

14 $47097 \mathrm{a} 83 \mathrm{ce} 8 \mathrm{~d}$

https://articulos.elmeme.me/as\%C3\%AD-se-vivi\%C3\%B3-el-tetazo-en-el-obelisco15 https://soyunachicamala.wordpress.com/2014/o6/18/mi-cuerpo-no-tiene-precio/

16 https://www.facebook.com/georgina.orellano/posts/1168378023230460 [22.11.2016]

\section{List of illustrations}

\begin{tabular}{|c|c|c|}
\hline Nini & URI & http://amerika.revues.org/docannexe/image/8061/img-1.jpg \\
\hline & File & image/jpeg, 120k \\
\hline & & AMMAR en la manifestación “Tetazo" 8-2-2017 en Buenos Aires'14 \\
\hline & & http://amerika.revues.org/docannexe/image/8061/img-2.jpg \\
\hline & File & image/jpeg, 64k \\
\hline & Title & Stencil callejero en Buenos Aires "mi cuerpo no tiene precio"15 \\
\hline (1) & Uي & http://amerika.revues.org/docannexe/image/8061/img-3.jpg \\
\hline & File & image/jpeg, 493k \\
\hline
\end{tabular}

\section{References}

Electronic reference

Santiago Morcillo and Karina Felitti, «"Mi cuerpo es mío”. Debates y disputas de los feminismos argentinos en torno al aborto y al sexo comercial », Amerika [Online], 16 | 2017, Online since 01 July 2017, connection on 24 September 2017. URL : http://amerika.revues.org/8061; DOI : 10.4000/amerika.8061

\section{About the authors}

\section{Santiago Morcillo}

Universidad de Buenos Aires (UBA)

Doctor en Ciencias Sociales por la Universidad de Buenos Aires (UBA) ; Licenciado y Profesor en Sociología por la Universidad Nacional de San Juan. Investigador asistente del Consejo Nacional de Investigaciones Científicas y Técnicas de la Argentina (CONICET) y docente de Psicología Social en la carrera de Sociología de la Universidad de Buenos Aires.

santiagomorcillo@gmail.com

\section{Karina Felitti}

Universidad de Buenos Aires (UBA)

Doctora en Historia por la Universidad de Buenos Aires (UBA). Docente de posgrado de esa universidad y en FLACSO Argentina). Es investigadora adjunta del Consejo Nacional de Investigaciones Científicas y Técnicas de la Argentina (CONICET) en el Instituto Interdisciplinario de Estudios de Género (IIEGE) de la Facultad de Filosofía y Letras de la Universidad de Buenos Aires.

karinafelitti@gmail.com 


\section{Copyright}

() Tous droits réservés 